\title{
Elevating Training Effectiveness: Exploring the Factors in the Learner's Environment that Influence Training Transfer
}

By

Michael E. Summers

A tremendous amount of money and effort is spent on designing and delivering training programs supporting business solutions and technology platforms to ensure employees (learners) understand and are able to use and adopt the newly acquired knowledge and skills. Training Magazine's 2019 Industry Report estimates that businesses in the United States collec tively spent $\$ 83$ billion on training last year (Freifeld, 2019). Some of which was used on retraining those who were unable to apply the learning back on the job. Of the most troublesome training related issues for organizations is that learners often struggle with transferring the new skills to their environment, reducing the overall effectiveness of the training program, acceptance and adoption of the new technology, and overall success of the implementation (Freifeld, 2019).

Training transfer is the process that occurs when workers apply the knowledge and skills learned in a training setting back on the job for which it was intended (Olsen, 1998). This process, which connects the training that a worker receives to their performance of assigned tasks, is at risk $80-90 \%$ of the time (Kim, 2004). The literature on learning and development indicates three major categories of factors that influence training transfer: learner characteristics, training design and delivery, and the work environment (Baldwin \& Ford, 1988; Cheng \& Ho, 2001; Lim \& Johnson, 2002). Furthermore, research reveals that the work environment is a key category of training transfer factors that is commonly overlooked by organizations (Merriam \& Leahy, 2005). It has been emphasized in literature that organizational, supervisory, and peer support contribute to the list of work environment factors, and when not present, are barriers to successful training transfer (Cromwell \& Kolb, 2004).

Keywords: Learning Application, Work Atmosphere, Climate, Trainee

Copyright ${ }^{\odot} 2021$ Michael E. Summers This article is published under a Creative Commons BY-NC license. Permission is granted to copy and distribute this article for non-commercial purposes, in both printed and electronic formats 


\section{Motivation for the Study}

Consistently changing job environments and requirements due in large part to the accelerating digital transformation of work and society has caused training transfer to surface as a major concern. The work environment of the learner has been found to contain factors that play a big part in training application. The training setting and support of the organization by way of human resource (HR) systems, financial and non-monetary rewards, the structure of the job, the support of senior leadership, the learner's immediate supervisor and peers, and the presence of the appropriate technology and ample time to practice learned skills are all factors that form what is referred to in this study as the transfer climate (Campbell et al., 1970). Many researchers have established the transfer climate as important as training itself (Rouiller \& Goldstein, 1993).The findings on training transfer by these researchers continue to hold true today as evidenced by the ongoing studies, learning conference presentations, and breakout sessions on the subject appearing on agendas; positioning it extremely well as a topic worthy of additional study for organizations desiring to increase the effectiveness of their training programs. With the knowledge of the factors that foster and support training transfer found in literature, this study aimed to find out which training transfer factors are absent from the worker's environment to explore why there are times when training transfer doesn't occur as intended.

\section{Research Question}

With the focus of this study on the training transfer factors within the learner's work environment in mind, the following single research question was created.

What factors are commonly absent from the learner's work environment which inhibit training transfer?

\section{Research Methods}

The study employed qualitative research methods. Two forms of data collection were conducted: (1) one-time, semi-structured interviews with leaders from credit unions and (2) one-time, semi-structured focus groups with front/back-office workers at the same credit unions who took place in learning events using the guided emergence format. The factors within the learner's environment discovered during the literature review that were found to influence training transfer formed the basis for the construction of the data collection instruments. The interview and focus group subjects were recruited from four credit unions to participate in the study. A manual coding process and an adapted thematic analysis process were employed to make sense of the data collected.

\section{Findings}

The analysis of the data collected from the interviews and focus groups revealed the absence of training transfer factors in the work environment for credit unions of varying size during technical training events. In doing that, it answered the single research question: What factors are commonly absent from the learner's work environment which inhibit training transfer? The factors were grouped and reported as four emergent themes: climate, leadership, support, and financial incentives. Climate included learning commitment, diversity, and sense of service; leadership included encouragement and change management; support included emotional support, peer support, and team environment; and financial incentives included financial performance incentives and financial incentives. The factors that were discovered to be absent within each theme were identified in the literature as important influential elements of the training transfer work environment (Baldwin \& Ford, 1988; Lim \& Johnson, 2002; Merriam \& Leahy, 2005). This implies that training transfer was not as successful as it could have been if the factors were present. An important highlight within the results was that two factor categories, learning commitment and diversity within the theme of climate, were unexpected findings and warrant future research.

\section{The Leader is the Key}

The overarching discovery from this research suggests the leader as the key controlling element of the work environment. As such, the leader influences the training transfer factors that are present (and absent) for the workers. If the findings presented in this dissertation can be shown to hold up, then training practitioners should encourage leaders in their organizations and the ones they serve to ensure the presence of the work environment transfer factors that are frequently found to be absent. This will help ensure that value of investments in training will be realized by effecting full training transfer.

\section{Research Strengths and Limita- tions}

The primary strength of the study was the qualitative methods chosen. The semi-structured interview and focus group data collection methods enabled the exploration of the training transfer factors within the work environment by creating the space to build rapport with the subject, which promoted rich dialogue and responses consisting of complete thoughts and not simple, binary answers. It also included a rigorous manual coding and thematic analysis process which produced emergent themes, sometimes 
including unexpected findings. The manual nature of the coding and analysis processes allowed for a very effective, hands-on approach, leading to the emergence of the four themes.

The sample size was the primary limitation in the study. With only four credit unions participating, the content saturation point which was expected to be reached from the interviews and focus groups was not achieved. The COVID-19 pandemic's significant impact on the general business environment across the country during the data collection process timeline placed additional limitations on the study, such as delays in the recruiting of subjects and the shift from in-person to virtual, online sessions.

\section{Conclusions}

The results of this study produced four emergent themes: climate, leadership, support, and financial incentive. The themes represent the groups of factors commonly found missing within the work environment surrounding training events; factors that act as enablers of transfer when present, and factors that, when missing, sometimes act as barriers to transfer. The results are congruent with the training transfer literature. They confirm the importance of training transfer factors. They also confirm that organizations should ensure the presence of the transfer factors within the learner's work environment for the successful application of training to occur.

The overarching theme and contribution of this study is that the leader is the primary factor and owns the ability to influence the presence or absence of the transfer factors. Furthermore, the results suggest measures leaders can take to position their workers for success in upcoming training events. Publications within the practices of human resources management, training and development, and management are available today to leaders who present articles on how to maximize the results from their training budgets. Leaders who consume that information learn why and how they can or should be ensuring these factors are present in their work environments today. From the results, it seems that organizations seem to arbitrarily pick the factors important to them, causing some that would benefit the employee to be disregarded. Whether this is based on their leaders' past experiences or on the budgetary capabilities, or on the lack of a formal training program within the organization, the decision to include or exclude factors is an unknown. It is therefore recommended that leaders of training functions within organizations educate themselves more on the topic of work environment transfer factors, and then sponsor the presence of them to increase the effectiveness of their training events and programs. A deeper understanding could be a valuable enabler for leaders to provide a work environment that will prepare and support their learners and be condu- cive to training transfer. Benefits to business include shortening the change curve during the transition to new platforms, increasing the adoption speed of new processes, decreasing expenses by reducing the need for re-training, and providing quality service are potentially within reach. Practitioners should make every attempt to ensure the presence of each of the factors in the learner's work environment for training transfer to be successful.

This study explored the training transfer factors that were commonly found to be absent during training. From this conclusion, the recommendations made here have the potential to extend the literature and the knowledge base on training transfer and positively impact business practice.

\section{References}

Baldwin, T.T., \& Ford, J.K. (1988). Transfer of training: A review and directions for future research. Personnel Psychology 41: 63-105. https://doi. org/10.1111/j.1744-6570.1988.tb00632.x

Campbell, J. P., Dunnette, M., Lawler, E, \& Weick, K. (1970). Managerial behavior, performance, and effectiveness. New York, NY, US, McGraw-Hill.

Cheng, E. W. L., \& Ho, D. C. K. (2001). A review of transfer of training studies in the past decade. Personnel Review 30(1): 102-118. https://doi. org/10.1108/00483480110380163

Cromwell, S. E., \& Kolb, J. A. (2004). An examination of work-environment support factors affecting transfer of supervisory skills training to the workplace. Human Resource Development Quarterly 15(4): 449-471. https://doi.org/10.1002/ hrdq. 1115

Freifeld, L. (2019). 2019 Training Industry Report. Training Magazine.

Kim, H. (2004). Transfer of training as a sociopolitical process. Human Resource Development Quarterly 15(4): 497. https://doi.org/10.1002/ hrdq. 1118

Lim, D. H., \& Johnson, S. D. (2002). Trainee perceptions of factors that influence learning transfer. International Journal of Training and Development 6(1): 36-48. https://doi.org/10.1111/14682419.00148

Merriam, S. B., \& Leahy, B. (2005). Learning transfer: A review of the research in adult education and training. PAACE Journal of lifelong learning 14(1): 1-24.

Olsen, J. H. J. (1998). The evaluation and enhancement of training transfer. International Journal of Training and Development 2: 61-75. https://doi. org/10.1111/1468-2419.00035 
Rouiller, J. Z., \& Goldstein, I. L. (1993). The relationship between organizational transfer climate and positive transfer of training. Human Resource Development Quarterly 4(4): 377-390. https://doi. org/10.1002/hrdq.3920040408

\section{Review}

This article was accepted under the constructive peer review option. For futher details, see the descriptions at:

http://mumabusinessreview.org/peer-review-options/

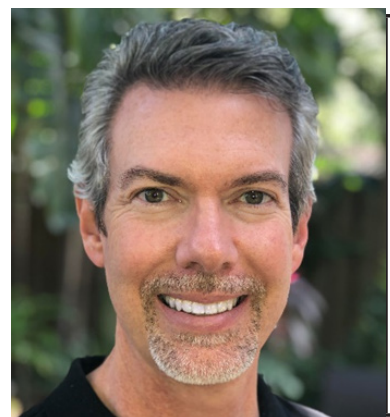

Michael E. Summers is the Senior Vice President of Learning and Organizational Development at PSCU, the nation's largest Credit Union Service Organization based in St. Petersburg, FL. His career journey in learning and development spans the U.S. Air Force and telecommunications and finance industries. He has practiced in the field for over 25 years as training designer, facilitator, technical writer, and organizational development, and has held expanding leadership positions along the way. He holds a Bachelor of Science degree in Workforce Education \& Development from Southern Illinois University. In December 2020, he received his Doctor of Business Administration degree from the University of South Florida's Muma College of Business. 